\title{
COMPOSIÇÕES DE FORÇA NA CONSTITUIÇÃO DE UM SUJEITO MODERNO: O INFANTIL
}

\author{
Dinah Quesada Beck1 \\ Paula Corrêa Henning2
}

\begin{abstract}
RESUMO
$\mathrm{O}$ artigo tem como objetivo pensar sobre os entendimentos de infância ainda tão vinculados ao processo de ingenuidade e pureza, bem como o processo de escolarização como salvacionista de uma infância imaculada. O texto se nutre das discussões sobre história da emergência especialmente em Michel Foucault. O estudo demarca a consistência moderna em que se gestou a população dos infantis de modo a educá-los e conduzi-los ao caminho do bem. Ao fazê-las carregar a noção de frágeis e dependentes, um imenso desejo de controlar e conduzir a vida das crianças arquitetou-se aos ideais do projeto educacional e civilizatório propagado desde o nascimento da Modernidade. É especialmente a partir desse momento histórico que os sujeitos infantis foram concebidos como indivíduos a conhecer, a desvendar, a esquadrinhar, necessitando, assim, estudá-los para melhor governá-los.

Palavras-chave: Educação; Infância; Modernidade; Governo.
\end{abstract}

\section{COMPOSITIONS OF FORCE IN THE CONSTITUTION OF A MODERN SUBJECT: THE CHILD}

\begin{abstract}
This article aims reflecting about the perceptions we have about childhood, which are still related to the processes of ingenuousness and purity, as well as the schooling processes as being salvationist of an immaculate childhood. The text nurtures from the discussions about the history of emergence, mainly in Michael Foucault. The study delimits the modern consistency in which children have been raised in order to be educated and driven in the path of righteousness. By making children carry the notion of being fragile and dependent, a huge desire of controlling and conducting children's lives was planned in the educational and civilizatory project propagated since the birth of Modernity. Especially since this historical moment, children have been conceived as individuals to be known, unveiled and investigated, becoming necessary to know them better to better rule them. Keywords: Education; Childhood; Modernity; Government.
\end{abstract}

Pensar na história da Infância como parte constituinte da história da educação para entender os processos educacionais atuais na constituição dessa população é o objetivo deste artigo. Para isso, buscamos provocar o pensamento do leitor no intuito de rachar alguns conceitos ao longo da história tão caros de entendimento da constituição das crianças nestes tempos contemporâneos. Gostaríamos que nosso texto suscitasse pensar sobre questões ainda pouco problematizadas, como é o caso do entendimento de infância ainda tão colado ao processo de ingenuidade e pureza, bem como o processo de escolarização como redentor e salvacionista dessa infância imaculada. 
Assim, nosso artigo inicia evidenciando ao leitor o conceito de história que trataremos para mapear alguns acontecimentos e entendimentos de infância que produziram a sociedade ocidental. A seguir, buscaremos compor alguns traçados dessa história, no intuito de problematizar a constituição de um sujeito infantil governado. Adiante, apontamos as marcas educacionais necessárias a ser impressas nesse novo sujeito produzido na modernidade: o infantil. Para finalizar, trazemos algumas considerações tecidas neste texto.

\section{A História da Emergência: composições para pensar a Infância}

De que história estamos falando? A partir dos ensinamentos de Nietzsche e Foucault, tratamos aqui de uma história da emergência. Trabalhar com a emergência de uma coisa ou de um objeto é muito diferente do que buscar revelar sua origem. Uma história da origem se "esforça para recolher nela a essência exata da coisa, sua mais pura possibilidade, [...] sua forma imóvel e anterior a tudo o que é externo, acidental, sucessivo" (Foucault, 1990, p. 17). Uma história da emergência, por outro lado, pressupõe a relação de um conjunto de forças que estão em conflito, de uma série de práticas, de um conjunto de discursos que se conectando, possibilitam a emergência de algo, em um determinado tempo e espaço. Podemos pensar a emergência como

O princípio e a lei singular de um aparecimento [...] é a entrada em cena das forças; é sua irrupção, o salto pelo qual elas passam dos bastidores ao palco. Cada uma com o vigor e a jovialidade que lhe é própria. [...] Ninguém é, portanto, responsável por uma emergência; ninguém pode se auto-glorificar por ela; ela sempre se produz no interstício. (FOUCAULT, 1990, p. 24).

Aqui não há causa e consequência. Trabalhar a partir do entendimento de história proposto por Nietzsche e Foucault é muito mais complexo, pois significa "marcar a singularidade dos acontecimentos, longe de toda a finalidade monótona; [...] espreitá-los lá onde menos se esperava e naquilo que é tido como não possuindo história". (FOUCAULT, 1990, p. 15). Significa desnaturalizar, desessencializar para poder mostrar que as coisas, os acontecimentos e os objetos são produtos da história. Isso pressupõe tomar a história como um a priori, como único a priori possível e despedir-se de todos os demais. Ou seja, é entender que não há algo a ser desvendado ou descoberto como a sua essência, sua origem ou a sua natureza. O que há é uma história que possibilitou sua emergência.

O que pretendemos apresentar aqui é uma maneira, entre tantas outras, de contar uma história, que talvez venha a contribuir com a História da Infância. Há, sem dúvida, diferentes formas de fazê-la, porém sempre que a fazemos, realizamos um exercício bastante perigoso, que envolve escolhas, opções, inclusões e exclusões. A história nunca é aprendida de uma maneira direta e completa, ela nunca é totalitária. "A história seleciona, simplifica, organiza, faz com que um século caiba em uma página”. (Veyne, 1998, p.18). Esse processo de escolhas, de recortar algumas cenas e excluir outras, de dar destaque a certos acontecimentos e silenciar outros, é um exercício que está intrinsecamente relacionado com o sujeito que conta essa história, com suas experiências e com suas indagações, e por esse motivo não pode ser considerado um processo neutro. 
Ao fazer esse exercício analítico, servindo-nos de recortes e considerações pontuais de autores/as que também estudam a infância, não intentamos demarcá-lo como um processo linear atrelado ao progresso e decorrente do desenvolvimento social e cultural da humanidade. As histórias da infância são diversas, contadas e recontadas por autores/as e estudiosos/as de campos distintos e perspectivas variadas, o que nos possibilita afirmar que pertencimentos tais como religião, cultura, sociedade, raça, etnia, cor, classe social, época, entre outros, produzem entendimentos múltiplos, instáveis e heterogêneos sobre as infâncias. Por isso mesmo, o recorte que fazemos desta história das infâncias — ou daquelas que buscam narrá-la —, necessita ser compreendido em seu caráter de provisoriedade.

Assim, nessa narrativa, não faz sentido perseguir, conforme tentam tendências de ordem hegemônica e totalizante, enquadrar e fixar as crianças e suas infâncias como decorrências naturais e lineares da ordem da razão e produto da sociedade. Diante dessa assertiva, podemos dizer que a infância não é uma categoria homogênea, universal, fixa e naturalmente dada. Se existem e existiram diferentes modos de viver a infância, diferentes são, também, os modos de discorrer sobre ela, os quais se apóiam em campos como a medicina, a sociologia, a antropologia, a educação, o direito, a religião, a psicologia, a filosofia, etc. e são perpassados pelos distintos contextos em que estão inseridos.

Utilizamos algumas passagens dessa história, mas acreditando que elas são construções sociais e culturais, estando em permanente reconstrução. Se assim considerarmos, perceberemos que inventamos a infância e que diversos significados foram (e são) atribuídos a ela, fazendo-nos percebê-la, entendê-la, nomeá-la e constituí-la, de diferentes formas. Percebemos a utilidade dos recortes dessa história, que aqui serão apresentados em termos de análise e problematização, no intuito de grifar no texto que em diferentes locais e épocas, as infâncias e as crianças foram constituídas e moldadas de modos diversos e para determinados fins. Também, para que enquanto educadores/as possamos estabelecer relações entre o que hoje temos pensado, arquiteturado e elaborado para as infâncias, com os sentidos múltiplos que ao longo de alguns séculos foram sendo produzidos para elas.

Do mesmo modo, é nosso interesse desnaturalizar a ideia de que as crianças sempre foram percebidas como sujeitos dignos e merecedores de cuidado, zelo e atenção, ou ainda, como seres frágeis, dóceis e inocentes. Esse entendimento nos levará a um exercício analítico sobre a emergência do conceito de infância no campo educacional. Perceberemos, pois, que rupturas e descontinuidades fazem parte dessa história e mesmo que as práticas contemporâneas direcionadas às crianças sejam diferentes das de outrora - tão logo vemos crianças consumindo, argumentando, questionando, desejando, embelezando-se, discordando, interpelando-nos —, ainda carregam consigo o caráter de antigamente, uma vez que se encontram atreladas ao paradigma moderno. Há, em tais práticas, mesmo que guiadas por um novo modo de agir das crianças, um imenso desejo de conduzir a infância para fins específicos. As práticas se diferenciam, o tempo e o espaço também; no entanto, as estratégias para/com as crianças ainda nos parecem ser as mesmas, muito próximas das de outrora: "discipliná-las", "governá-las" e "controlá-las". (Narodowski, 1994; Corazza, 2002, 2004; Bujes, 2002, Varela, 1994; Varela e Alvarez-Úria, 1992).

Sendo assim, provocamos uma rachadura no entendimento de verdade. Ela é entendida aqui como algo produzido por nós, em cada momento histórico. Não mais vista como algo a descobrir, desvelar e revelar o real, a verdade toma a posição de algo inventado, produzindo seu próprio objeto. Sua criação, dentro de uma ordem discursiva, assume a posição de legitimidade. Assim, importa é que o dito esteja "no verdadeiro", 
nessa "polícia discursiva" de que trata Foucault (2004). A verdade é algo que nós próprios criamos, fazendo-a ter efeitos de sentido, efeitos de realidade, produzindo as verdades. Com isso, o discurso torna-se um artefato que produz coisas que vão compondo o cenário de determinado momento histórico. Esses discursos só são possíveis de existir em dado período, pois existe um feixe de relações que os compõe, tornando verdade seus ditos.

Escapando da origem primeira da história, Foucault nos convida a entendê-la como documentária, mas não de uma forma linear, cronológica, mas embaralhada, riscada, reescrita e, por isso mesmo, essa história, "exige paciência". A história está aí não para cultivar e cultuar ídolos e deuses. Ao contrário, ela é uma das ferramentas para "rir da solenidade das origens" (Foucault, 1990, p. 18). Desmontando uma história das origens, da verdade, Foucault, na esteira de Nietzsche, nos ensinou a olhar os acidentes, os percalços, os desvios, as recorrências e as dispersões dos acontecimentos. Uma história que diz muito de nós, dos nossos olhares sobre os objetos que criamos, das coisas que pensamos, das práticas que efetuamos. Assim, dão as costas à essência das coisas, pouco se interessam com os fatos, a Verdade verdadeira da história. Ela deve ser pensada, isto sim,

[...] a partir de um problema que se coloca no presente e, para a resolução, necessita voltar-se ao passado; mas, também, aqui, é de uma nova relação com o passado que se trata, um passado não visto como embrionário, como germe a partir do qual tudo evolui, mas nietzscheanamente falando, como "origem baixa", lugar do acontecimento, da emergência em uma singularidade, a partir da disputa de forças em conflito. (RAGO, 2005, p. 263, grifos da autora).

Parece-nos sugestivo o convite de fazer da história um campo de saber de irrupções, descontinuidades e emergências. Entretanto, o convite para a criação de uma nova história é instigante, na medida que, em o aceitando, somos jogados a dançar na beira do abismo[...] "equilibrar sobre tênues cordas e [criar] possibilidades e dançar até mesmo à beira de abismo". (NIETZSCHE, 2001, p.241).

Por isso, o recorte que fizemos dessa história da infância, necessita ser compreendida em seu caráter de provisoriedade. A infância, nessa perspectiva, não é tomada como homogênea, fixa, naturalmente dada, nem ocupa a categoria de universal. Do mesmo modo, não desconsidera aspectos como classe social, raça, etnia, cor, religião e se vê perpassada por estes e outros marcadores que são múltiplos, instáveis e heterogêneos, modificados de acordo com os distintos contextos em que estão inseridos. É nesse sentido que convidamos o leitor a provocar o pensamento e compor outras possibilidades de entender a infância como um construto humano, demasiado humano.

\section{Crianças e Infâncias: marcas de ausência e emergência em suas constituições}

[...] A criança não é nem antiga nem moderna, não está nem antes nem depois, mas agora, atual, presente. Seu tempo não é linear, nem evolutivo, nem genético, nem dialético, nem sequer narrativo. A criança é um presente inatual, intempestivo, uma figura do acontecimento. E só a atenção ao acontecimento, como o incompreensível e o imprevisível, que pode levar a pensar uma temporalidade descontínua. (LAROSSA, 2001, p. 284). 
Como refere o Estatuto da Criança e do Adolescente - ECA (Lei Federal 8.069/1990), crianças são os sujeitos compreendidos na faixa etária dos zero até os doze anos de idade incompletos. Se, por um lado, a idade serve como um marcador contemporâneo para que possamos conhecer os sujeitos da infância, podemos, ao mesmo tempo, perspectivar algumas considerações sobre a mesma. Contemporaneamente, ao conhecer os sujeitos criança, gozadores da infância, identificamos práticas, locais, cuidados, atenção e amparo que histórica, cultural e socialmente temos construído para as crianças ao vivenciarem suas infâncias. Paradoxalmente, mesmo tendo feito essa sucinta reflexão, nos deparamos com a conjuntura da sociedade brasileira, local em que este estatuto vigora. Pobreza, desigualdade, escassez, precariedade, exclusão, fazem-nos perceber que a idade é apenas um marcador, dentre tantos outros que nos levam a apontar que as infâncias brasileiras são vividas 'dos zero aos doze anos de idade incompletos', conforme a lei delega, de modos muito distintos e variados.

Esse período da infância, de caráter multifacetado - marcado por diversas práticas e instâncias - precisa ser analisado em consonância com as inúmeras transformações que se deram na sociedade, em especial, desde a Idade Média e, adiante, na Modernidade ${ }^{3}$, tomando impulso com os atos da Revolução Industrial.

No entanto, ainda que seja temerário afirmar que a infância - atendida, amparada e preconizada - fora uma construção e invenção moderna é preciso considerar que foi pela Modernidade que se constituíram discursos e representações sobre a infância, modificando o panorama de atendimento, amparo e compreensão que se tinha sobre a mesma. As modificações que estavam a se delinear naquele momento social, econômico e cultural, marcadas pelos anseios revolucionários, possibilitaram a emergência de tais discursos e representações.

Autores como Philippe Ariès (1981), que tratam da história da infância e da família, descrevem que anterior ao período histórico da Revolução Industrial, compreendido entre os séculos XII e XVII, a vida das crianças ainda era muito engajada com a vida e com as práticas desenvolvidas pelos adultos. Sua obra é considerada uma precursora nos estudos da infância, da criança e da família. Ariès foi um dos pioneiros a discutir sobre a infância minorada e pouco atendida em sociedades tradicionais de séculos anteriores, as quais davam um caráter de adultez para as crianças. Por isso, a contribuição de seus estudos para o campo da infância é significativa por ter nos auxiliado a problematizar diferentes traçados e nuances de como a infância fora representada desde a Idade Média até a Modernidade.

Registros históricos e icnográficos destacados pelo autor mostram-nos que as crianças diferenciavam-se dos adultos pela sua estatura. Suas vestimentas seguiam os mesmos estilos e moldes das dos adultos, caracterizando a atribuição inferior que a elas era conferida. Além de suas roupas, outros traços que demonstram a precariedade das condições em que eram criadas encontram abrigo na alimentação inadequada e limitada recebida (suas refeições eram após as dos adultos); os péssimos hábitos de higiene da época (quando tomavam banho, por exemplo, era na água em que homens, primeiramente, e mulheres, secundariamente, já haviam se banhado); a inexistência de cuidados médicos e sanitários (como a vacinação); entre outros fatores, que nos levam a considerar, conforme faz a pesquisadora Sandra Corazza (2002), que a história das crianças na Idade Média deuse no "apagamento". As crianças, tais como hoje compreendemos, denominamos e nomeamos, nem sempre existiram e, por muitos anos, viveram na escuridão e no anonimato de sua própria infância. Talvez, a naturalidade com a qual hoje lidamos com o 
sentimento de pertença e cuidado para/com as crianças, dificulte-nos de considerar que por muitos séculos esses seres foram negligenciados.

Naquele período, pela precariedade das condições sócio-culturais de vida da época, a mortalidade infantil tinha índices muito elevados. Do mesmo modo, práticas de infanticídio, nas quais crianças eram largadas, mortas, jogadas e até mesmo dadas de alimento aos animais, eram muito comuns. Segundo Verônica Müller (2007), as práticas de infanticídio eram aceitas e reguladas como parte do mecanismo social não só como uma forma de controlar a comida destinada à população, como também como uma estratégia de controle e de diminuição da própria população. "O fato de nascer do sexo feminino foi muitas vezes também motivo para a morte" (Müller, 2007, p. 34). As crianças eram seres/objetos passíveis de serem substituídos, descartados. A família, lugar social de sentimento, afeto e valor como hoje a denominamos, naquela época, evidenciava ausência de qualquer destes pertencimentos para/com as crianças.

As crianças sobreviventes também incorporavam a atribuição de insignificância, menor importância e invisibilidade pela proximidade que se estabelecia entre as regras e convenções sociais destinadas a si e, também, aos adultos. Os poucos e precários cuidados que lhes eram destinados viam-se resumidos até a faixa etária dos sete anos de idade, período em que tais sujeitos já assumiam a posição de adulto jovem, tendo em vista já serem capazes de realizar de modo independente algumas atividades que antes fugiam de suas condições.

Nos rudimentos desse contexto, as crianças portavam-se e divertiam-se como adultos e a proximidade entre esses seres não se encerrava em apenas considerar as crianças como inexistentes à sua própria infância. Por não haver, tal como temos hoje, a noção de privacidade, crianças e adultos conviviam em todas suas peculiaridades. $\mathrm{O}$ modelo arquitetônico da época não promovia a necessidade de separação entre adultos e crianças e, nesse sentido, como em grandes aglomerados, famílias numerosas conviviam sem pudores e reservas, não havendo o resguardo dos pequenos de determinadas práticas, inclusive as sexuais.

Mesmo num caráter de apagamento e invisibilidade, sem o sentimento de pertença, amor, amparo e cuidado que às crianças delegamos hoje, percebe-se que a figura do adulto foi e representou, de certo modo, um modelo para a infância. Diz-se isso ao ponderar, conforme faz Ariès (1981), a relação de proximidade que se propunha entre adultos e crianças a partir do momento em que estas já demonstravam determinados desembaraços físicos e intelectuais, tais como falar e caminhar, que as permitiam não apenas conviver, mas interagir com o mundo adulto.

Ao final do século XVI e início do século XVII, com o fortalecimento da família nuclear burguesa (pai, mãe e filhos/as), é que outra conotação à infância passou a se gestar: as mudanças sociais e culturais na sociedade europeia foram consolidando toda uma preocupação em torno da criança, possibilitando essa descoberta da infância. Apenas séculos mais tarde, juntamente com os impulsos da Revolução Industrial e do desenvolvimento do Capitalismo é que se tornaram possíveis tais configurações sociais e culturais destinadas às crianças.

Tais mudanças na conjuntura social permitiram, às crianças, saírem do anonimato e passarem ao reconhecimento, assumindo o status de membros sociais. Com isso, a criança passava a ser vista como parte importante de sua família, da sociedade e do Estado, bem como da Igreja. A emergência de práticas e locais constituídos e destinados por esses setores e ramos, inevitavelmente, levaram a uma mudança no relacionamento estabelecido entre adultos e crianças. 
No contexto familiar — sendo, agora, os adultos da família os responsáveis primeiros pelo zelo das crianças e da sua educação - a noção de separabilidade e a disposição dos cômodos da casa foram os principais resultantes dessa necessidade de mudança no comportamento entre adultos e crianças. A infância passava a representar um período de pureza na vida das pessoas, o qual devia ser preservado.

Por isso, a necessidade de restringi-las de uma série de práticas desenvolvidas pelos adultos, como as sexuais, também começava a emergir nesse período, acarretando a difusão de práticas para serem vivenciadas por esses mesmos sujeitos, mantendo-os ocupados com outras tantas funções/atribuições. O bem-estar da criança não se via, naquele momento, acompanhado de práticas de entretenimento, tais como as temos hoje. Encontravam-se, na sua grande maioria, envolvidas com atribuições do lar e, também, com uma educação de cunho moralizante e religioso.

No exercício dessas práticas descritas de educação e de cuidados com o corpo uma espécie de "governamento"4 (Bujes, 2002) da população infantil foi se fortalecendo. Vinculado a esse exercício de governo percebe-se a produção de um conceito em torno da infância, marcado pela forte aproximação (em caráter diferenciado do de antigamente) e relação de dependência entre adultos e crianças.

Se nos âmbitos social e familiar os laços entre crianças e adultos foram sendo reconstituídos e fortalecidos, práticas, instituições e campos do saber passaram a se proliferar e a instaurar cartografias de procedimentos para as crianças. Há, a partir desse período, um profícuo investimento na produção de discursos científicos que descrevem, nomeiam e analisam as crianças e suas infâncias, no intuito homogeneizá-las e regulá-las. (Varela, 1994). É, nesses moldes, que a educação escolar entra nesse jogo, nessa relação.

\section{Educação Escolar: Emergências de Governo à Infância}

A relação de dependência entre adultos e crianças, promovida desde o apogeu da Modernidade, demarcou a necessidade das crianças serem, cada vez mais, cuidadas e educadas. Essa preocupação com os infantis possibilitava que a instituição escolar fosse organizada para os fins de instrução, normatização e moralização. O processo regulatório, com vistas ao controle dos infantis, promoveu a constituição de outros saberes sobre as crianças, tais como os gestados com a categoria aluno.

A escola, como local destinado aos cuidados e à educação dos infantis, representou, em certo grau, a separabilidade entre crianças e adultos da família, com vistas ao ingresso dos pequenos num contexto de escolarização e institucionalização do saber. (Varela e Alvarez-Úria, 1992). Vale ressaltar que este sujeito estudantil, com a educação oferecida, naquele contexto, estava muito mais vinculado a uma formação moral e religiosa, do que propriamente numa educação convertida em útil para a sua vida. Nesse sentido, resumia-se numa educação com vistas a assegurar a inocência e fragilidade das crianças ${ }^{5}$, distanciando-as dos pecados da carne, dos males e dos desvios da sexualidade, no intuito de constituir virtuosos cidadãos, seres maduros, racionais, normais e completos. (Corazza, 2002).

Desse modo, em especial pelo final do século XVIII e pelo século XIX, embalados pelos anseios revolucionários de se ter uma sociedade produtiva e em desenvolvimento, é que diferentes métodos disciplinares em torno dos corpos infantis - os quais eram vistos como máquinas produtoras de energia - começaram a se fortalecer e produzir em torno da educação às crianças ofertada, caracterizando os ideais do paradigma moderno. 
A aprendizagem das crianças compreendida num caráter mais institucional também passou a ser prioridade. A educação, que outrora se dava através do convívio direto com os adultos da família, passou a se efetivar num local específico: a escola. Paulatinamente, as famílias foram sendo estimuladas pela Igreja e pelo Estado a colocar seus/as filhos/as nessa instituição.

O processo de escolarização converge com o processo de controle e regulação da infância e, conforme apontam Júlia Varela e Fernando Alvarez-Uría (1992) denomina-se numa espécie de "maquinaria do governo da infância". Deste modo, a constituição de um conjunto de saberes e de expertises emerge como elemento fundamental para a condução da educação das crianças.

Juntamente à educação oferecida pela família, cada vez mais se tornava necessária a existência de uma educação com características pontuais e peculiares, sendo mais disciplinar, no sentido de estabelecer normas e regras para a vida e para o comportamento social, que contribuísse com o progresso econômico daquela sociedade, a qual deveria ser, agora, de responsabilidade da escola. Segundo Felipe (2000, p. 58):

[...] muitos pais foram criticados por não serem rígidos o suficiente com seus filhos e filhas. A escola poderia então fornecer este aparato disciplinar, entendido como necessário à vida em sociedade. Parecem se delinear, em certa medida, as concepções de que a formação dada pela família não seria mais suficiente para educar sua prole, sendo imprescindível recorrer às escolas.

Nesse sentido, o conceito de infância assumia outra conotação, uma vez que a criança, além de ser vista como um ente da família merecedor de cuidados, proteção e amparo, passava a ser vista como o centro, o rumo e o porvir da sociedade. Por esse motivo, em meados do século XIX, a difusão do processo de escolarização foi um dos acontecimentos/marcadores que sinalizou essa atenção dada à criança escolarizada e que representou um importante aspecto da modernização das sociedades.

Tendo se efetivado juntamente à Revolução Industrial, o processo de escolarização também é examinado como responsável por todo um investimento sobre a infância, uma vez que seu maquinário e discurso pedagógico difundiram-se como um modo de expandir a educação familiar e religiosa e, também, exercer práticas de controle e regulação sobre este público. Era gestada a categoria aluno, que mais adiante passaria a ser alvo de conhecimento, por parte de diversas áreas e campos do saber (pedagogia, psicopedagogia, pediatria, fonoaudiologia, psicologia, etc.).

Tais áreas, representantes da Ciência, paulatinamente, compuseram um vasto saber que trata de conhecer a criança, tendo vistas de, cada vez mais e melhor, poder conduzi-las, discipliná-las, regulá-las, educá-las. Muitos estudos e pesquisas passaram a tomar as crianças como objeto de estudo e a infância como campo de investigação, consagrando o discurso pedagógico propagado na escola até hoje. É importante salientar, nessa narrativa, que foi durante este período histórico e na proliferação desses estudos promovidos pelo corpo de especialistas, que se constituiu um entendimento sobre as crianças marcado pela presença da homogeneidade.

No interior das escolas, para que a educação de sujeitos e seus corpos tivesse êxito, mecanismos de classificação, seriação, ordenamento e hierarquização faziam-se presentes. Com eles rituais, calendários, lições, exercícios, regularidade de horários, divisão das crianças pela sua faixa etária e pelo sexo em determinados espaços, preconizavam uma 
uniformidade nos modos de educar. A instituição escolar entendia e produzia isso em seu exercício. E é dessa forma que a pedagogização da infância, ou ainda, o projeto educacional disseminado pela Modernidade passou a ser compreendido como um "projeto civilizador" (BUJES, 2002, p. 55),

O projeto educacional moderno é um projeto civilizador: estabelecer novas pautas de conduta para os seres humanos. Seu principal objetivo foi o de operar o distanciamento entre homem e natureza _ - vista como um estado de selvageria —, individualizando cada vez mais o sujeito. A noção moderna de infância [...] se difundiu e foi apropriada por outras instâncias e instituições sociais, esteve associada à produção de novos modos de educação para os sujeitos infantis, especialmente voltado para a institucionalização das crianças.

Essa maquinaria — disciplinar, civilizadora, governante e pedagógica introduziu instâncias e ações no interior das escolas para seu pleno funcionamento. Maquinaria essa que ainda hoje, de outras formas e revestida por estratégias e táticas variadas, posicionam-se instauradas na escola com vistas à fabricação de seus indivíduos escolarizados.

Louro (2007a, p. 58), ao fazer referência à escola como uma instituição legada pela sociedade ocidental moderna, que fabrica diferenças entre os indivíduos no processo de escolarização desses sujeitos e seus corpos, afirma que:

A escola delimita espaços. Servindo-se de símbolos e códigos, ela afirma o que cada um pode (ou não pode) fazer, ela separa e institui. Informa o "lugar" dos pequenos e dos grandes, dos meninos e das meninas. Através de seus quadros, crucifixos, santas ou esculturas, aponta aqueles/as que deverão ser modelos e permite, também que os sujeitos se reconheçam (ou não) nesses modelos. O prédio informa a todos/as sua razão de existir. Suas marcas, seus símbolos e arranjos arquitetônicos "fazem sentido", instituem múltiplos sentidos, constituem distintos sujeitos. (Grifos da autora).

Fora a partir do século XIX que os discursos sobre a escola passaram a assumir centralidade no corpo social. A escola passou a ser vista como $a$ instituição destinada e responsável pela educação de crianças e jovens, aquela que seria capaz de produzir sujeitos integrados na sociedade, comprometidos com o avanço e o progresso social. Ou seja, a escola era capaz (tinha o poder) de constituir sujeitos disciplinados.

Michel Foucault (1987, 1990) chamou de "poder disciplinar" o exercício de determinadas técnicas de poder que incidiam sobre os indivíduos o ordenamento, a vigilância, a sansão normalizadora e o autoexame, sendo consideradas eficazes pelo seu caráter de positividade, uma vez que "vigiar era mais econômico do que punir". Tornavase preciso governar os corpos e as almas, contribuindo para o progresso e para a civilidade dos sujeitos na sociedade. Para isso, era necessário conhecer e controlar no detalhe a população a ser governada por meio da educação. A escola, que nesse período emerge como uma instituição de governo ${ }^{6}$, no exercício de sua pedagogia, tomou para si o uso de tais técnicas.

Com esse entendimento, da eficácia da escola para a difusão de códigos morais, a noção de infância que se disseminava pela sociedade estava associada aos processos de 
institucionalização das crianças aos novos modos necessários de poder educá-las e, logo, civilizá-las. A escola envolveu-se (e ainda envolve-se) na produção de um conjunto de saberes advindos dessa vontade de saber sobre a infância.

Desse modo, pelo século XIX e na primeira metade do século XX - o qual emergia embalado por esta profusão científica - muito se escreveu sobre a criança e sobre a sua infância, sobre $a$ educação que essas deveriam receber por parte das escolas e das famílias, como era $o$ modo pelo qual elas aprendiam, quais eram as etapas percorridas em seu desenvolvimento biológico, intelectual, emocional, afetivo, social, sexual e, com isso, inúmeros discursos sobre esses sujeitos passaram a ser produzidos e postos em circulação, num caráter universal e homogeneizante.

Nesse sentido, é interessante observar algumas de suas marcas culturais e sociais. Se ao final do século XIX, determinadas circunstâncias econômicas e políticas foram o principal motivo para se acelerar o processo de escolarização das crianças, compreendendo a necessidade de uma educação formal não apenas dada no seio familiar, mas que também fosse profissionalizante e preparasse esses sujeitos para o trabalho - reflexos da Revolução Industrial; por outro lado o processo de escolarização, no século XX, pareceu seguir, sob outras fendas, na mesma perspectiva. Ou seja: a educação formal, inscrita na contemporaneidade, teve/tem suas práticas pedagógicas revestidas por uma espécie de novo código de civilidade. A partir de então — meados do século $\mathrm{XX}$ —, tal código tem fixado a necessidade de uma educação/formação integral para a constituição de um sujeito autônomo, independente, reflexivo, ético, integrado na sociedade e capaz de tomar decisões e intervir. A escola, que até pouco tinha a responsabilidade de dar prosseguimento à educação moral, religiosa e familiar, ocupando majoritariamente a posição de locus do saber, hoje, contribui na constituição desse sujeito moderno desejado, passando a ser vista como uma instituição, dentre tantas outras, envolvida em um processo educativo disciplinador.

\section{Provocações Finais}

Em linhas gerais, esses foram alguns dos aspectos que deram consistência a determinados entendimentos que passaram a se gerar sobre a infância, marcando significativamente a história das crianças e o modo de educá-las e conduzi-las ao longo dos últimos séculos. Os inúmeros entendimentos acerca desse conceito e suas significativas transformações estiveram/estão imbricados com determinados acontecimentos que marcaram a sociedade moderna e ocidental. Desse modo vemos a centralidade desses traçados históricos na configuração de distintos modos de ser criança e na constituição das identidades da infância.

Nesse apanhado histórico que delimitamos, vimos que as crianças passaram a ser compreendidas como sujeitos dignos de atenção, por parte dos adultos. Nesse processo, parece-nos que a educação, seja ela escolarizada ou familiar, com anseios de educar as crianças para o progresso da sociedade, teve caráter decisório no governo da infância.

No entanto, ainda que tenhamos a compreensão de que inúmeras e profundas transformações se posicionaram no corpus social, alterando a paisagem das relações pessoais, sociais, familiares, dentre outras tantas, ainda podemos verificar que fora desde os idos da Idade Média, que se constituiu, ainda que de diferentes formas das de hoje, um imenso desejo de controlar e conduzir a vida das crianças. Ao fazê-las carregar a noção de frágeis e dependentes, potencialmente promovida na Modernidade, encontramos auxílio e subsídios para que, contemporaneamente, continuemos a arquiteturar, destinar, arguir e 
decidir, coisas para as crianças e suas infâncias, caracterizando, desse modo, os ideais do projeto educacional, social e civilizatório propagado desde os séculos passados.

$\mathrm{Se}$ as crianças, a partir de determinado momento, em especial com a institucionalização das escolas como locais de formação da identidade, controle e disciplina, foram concebidas como sujeitos a saber, a conhecer, a desvendar, $a$ esquadrinhar, que seria preciso conhecê-las melhor para poder governá-las, indagamos: que outras formas, arranjos e configurações o disseminado projeto civilizatório, educacional e moderno ganha de contornos e nuances na constante produção dessa história das infâncias pela contemporaneidade? Quais são as outras formas de construir e conceber as infâncias? Que condições de possibilidade emergem? As infâncias, entendidas como objetos constituídos discursivamente, são interpeladas por quais representações sociais e culturais? Eis questões que nos suscitam ao finalizar este artigo. Muito bem, deixemo-as em suspenso para outros atravessamentos e escritas.

\section{Referências}

ARIÈS, Philippe. História social da criança e da família. Tradução de Dora Flaksman. Rio de Janeiro: LCT - Livros Técnicos e Científicos Editora S.A., 1981. BRASIL (1990). Lei Federal 8.069, de 13 de julho de 1990. Estatuto da Criança e do Adolescente, 1990. Disponível em http://www.planalto.gov.br/ccivil_03/Leis/L8069.htm. Acesso em: 20/09/2010.

BUJES, Maria Isabel E. Infância e maquinarias. Rio de Janeiro: DP\&A, 2002.

CORAZZA, Sandra. História da Infância sem Fim. Ijuí: Editora Unijuí, 2004. 2002. Infância \& Educação. Era uma vez... quer que conte outra vez? Petrópolis: Vozes,

FELIPE, Jane. Erotização dos corpos infantis. In: LOURO, Guacira; FELIPE, Jane; GOELLNER, Silvana (Orgs). Corpo, Gênero e sexualidade: um debate contemporâneo na educação. Petrópolis: Vozes, 2007, p. 53-65.

. Governando mulheres e crianças: Jardins de infância em Porto Alegre na primeira metade do século XX. Porto Alegre: UFRGS, 2000 (Tese de Doutorado). FOUCAULT, Michel. A ordem do discurso. Tradução de Laura Fraga de Almeida Sampaio. 10a ed. São Paulo, Edições Loyola, 2004. Editora, 1990.

Microfísica do Poder. Tradução de Roberto Machado. Rio de Janeiro: Graal

Vigiar e punir: história da violência nas prisões. Tradução de Raquel Ramalhete. Petrópolis: Editora Vozes, 1987.

LARROSA, Jorge. Dar a palavra. Notas para uma dialógica da transmissão. In.: LARROSA, Jorge; SKLIAR, Carlos (Orgs.). Habitantes de Babel: políticas e poéticas da diferença. Belo Horizonte: Autêntica, 2001, p. 281-295.

LOURO, Guacira Lopes. Pedagogias da Sexualidade. In: LOURO, Guacira Lopes (Org.) O corpo educado: pedagogias da Sexualidade. Belo Horizonte: Autêntica, 2007, p. 8-34. 
Currículo, gênero e sexualidade. O "normal", o "diferente" e o "excêntrico". In: LOURO, Guacira Lopes.; FELIPE, Jane; GOELLNER, Silvana Vilodre. Corpo, gênero e sexualidade: um debate contemporâneo na educação. Petrópolis: Vozes, 2007a , p. 41-52.

MÜLLER, Verônica. História de Crianças e Infâncias - registros, narrativas e vida privada. Petrópolis: Editora Vozes, 2007.

NARODOWSKY, Mariano. Infancia y Poder - La confirmacion de La Pedagogia. Buenos Aires: Editora Aique, 1994.

NIETZSCHE, Friedrich. A gaia ciência. Tradução de Jean Melville. São Paulo:

Companhia das Letras, 2001.

RAGO, Margareth. Libertar a história. In: M. Rago; L. OrandiI, A. Veiga-Neto (Orgs.). Imagens de Foucault e Deleuze: ressonâncias nietzschianas. Rio de Janeiro: DP\&A Editora, 2005, p. 255-272.

VARELA, Júlia. O Estatuto do Saber Pedagógico. In: SILVA, Tomaz Tadeu da (Org.). O Sujeito da Educação: Estudos Foucaultianos. Petrópolis: Vozes, 1994, p. 87-96.

; ALVAREZ-ÚRIA Fernando. Maquinaria escolar. Teoria \& Educação, Porto

Alegre, n. 6, 1992, p. 12-69.

VEYNE, P. Como se escreve a história e Foucault revoluciona a história. Tradução de Alda Baltar e Maria Auxiadora Kneipp. $4^{a}$ ed. Brasília: Editora Universidade de Brasília, 1998.

\section{Notas}

1 Professora Adjunta do Instituto de Educação e do Programa de Pós-Graduação em Educação da Universidade Federal do Rio Grande. Pedagoga, Mestre e Doutora em Educação pela Universidade Federal do Rio Grande - FURG, Universidade Federal de Pelotas - UFPel e Universidade Federal do Rio Grande do Sul - UFRGS, respectivamente. Atua principalmente nas temáticas de Gênero, Currículo, Cultura, Infância e Formação de Professores. Pesquisadora do GESE/FURG e do GEERGE/UFRGS. dinahqbeck@gmail.com

${ }^{2}$ Professora Adjunta do Instituto de Educação, do Programa de Pós-Graduação em Educação Ambiental e do Programa de Pós-Graduação Educação em Ciências da Universidade Federal do Rio Grande. Pedagoga, Mestre e Doutora em Educação pela Universidade Católica de Pelotas, Universidade Federal de Pelotas e Universidade do Vale do Rio dos Sinos - UNISINOS, respectivamente. Atua principalmente nas temáticas de Educação Ambiental, Estudos Foucaultianos, Currículo e Formação de Professores. paula.henning@ig.com.br

\footnotetext{
${ }^{3}$ A primeira tentativa de caracterização da Modernidade pode descrevê-la como um ideário ou, ainda, como uma visão de mundo. Tal concepção está relacionada ao projeto de mundo moderno, instaurado ao longo da Idade Moderna e consolidado com os atos da Revolução Industrial. Por essas razões a Modernidade, no Ocidente, está igualmente relacionada com o desenvolvimento do Capitalismo. A Modernidade se revela carregada de ambiguidades, e tudo isso devido às profundas transformações sociais, econômicas e políticas que ocorreram, sobretudo, entre o início do século XVIII até os dias atuais.
}

${ }^{4}$ Governamento é um termo foucaultiano muito utilizado por Maria Isabel Bujes em seu estudo arqueológico que deu origem ao livro Infância e Maquinarias. Com o uso desse termo a autora busca exprimir o conjunto de táticas, técnicas e procedimentos aplicados, ao longo dos anos, de forma bastante eficaz, sobre a população infantil, no intuito de constituí-las como sujeitos disciplinados.

${ }^{5}$ Nesse contexto de educação moralizante para as crianças, vale ressaltar as diferenciações que se produziam entre os gêneros: enquanto os meninos recebiam educação/instrução para ingresso nas relações sociais e de 
trabalho, as meninas eram exercitadas para serem boas esposas e donas do lar, mães zelosas e cuidadosas. Sobre esses aspectos encontramos uma série de pesquisas situadas dentro dos Estudos de Gênero. Citamos as desenvolvidas pela pesquisadora Guacira Lopes Louro, como as representadas em seu livro "Gênero, sexualidade e educação - uma perspectiva pós-estruturalista” (Vozes, 2007).

${ }^{6}$ Governo é aqui compreendido não apenas em seu sentido burocrático, mas também como uma forma de exercer controle e regulação sobre a população. Sobre o assunto, ver: Foucault, M. (1987). Vigiar e Punir: história da violência nas prisões. Petrópolis: Vozes. Foucault, M. (2008). Segurança, Território e População. São Paulo:Martins Fontes.

Recebido em junho-13

Aprovado em novembro-13 